\title{
Quantum chemistry-based verification of antioxidative action of iodide in mitochondria
}

\author{
Shozo Yanagida ${ }^{1 *}$, Akio Kaname ${ }^{2}$ and Nobuyuki Murakami ${ }^{3}$ \\ ${ }^{1} \mathrm{M} 3$ laboratory, Inc, ISIR, Osaka University, Osaka, Japan \\ ${ }^{2}$ Holistic Space Japan Medical \& Resort, Taiji, Wakayama, Japan \\ ${ }^{3}$ Holos Matsudo Clinic, Matsudo, Chiba, Japan
}

\begin{abstract}
Background: In view of the well-known health-care qualities of aqueous potassium iodide (KI), quantum chemistry-based molecular modeling, i.e., density functional theory-based molecular modeling (DFT/MM) is undertaken to understand how iodide ion ( $\mathrm{I}^{-}$) shows antioxidative properties on aqueous phosphorylation process in mitochondria (mt) of alive cells.

Materials and methods: We perform DFT/MM equivalent to the quantum mechanics/molecular mechanics (QM/MM) method, by using the B3LYP exchangecorrelation function and the 6-31G(d) basis set with Spartan'18 (Wavefunction, Inc. Irvine, CA).

Results: Iodide ion $\left(\mathrm{I}^{-}\right)$is in equilibrium with hydrogen iodide $(\mathrm{HI})$, being oxidized to hypoiodous acid (HOI) by ground state oxygen $\left({ }^{3} \mathrm{O}_{2}\right)$ or by hydrogen peroxide $(\mathrm{HOOH})$ in aqueous systems. DFT/MM also verifies that van der Waals force (vdW) induces van der Waal (vdW) aggregation of hypoiodous acid (HOI) with phenylalanine, resulting in giving tyrosine, and that vdW works strongly on aggregation of tyrosine with HOI, leading to formation of 2,6-diiodotyrosine via 2-iodotyrosine. 2,6-Diiodotyrosine as homolog of thyroid hormones T4 is validated to show antioxidative action to evil active oxygen in $\boldsymbol{m t}$, i.e., HOOH and hydroxyl radical.
\end{abstract}

\section{Introduction}

Iodine has long been known to be an essential trace element for disease-free life and longevity. Recent open access review articles and website documents on iodine mention that iodine as an elemental component of thyroid hormones is required at all stages of life especially during growth period $[1,2]$. In other words, thyroid hormones, i.e., tetraiodothyronine (T4 or thyroxine) and triiodothyronine (T3) are recognized to play an important role in general growth and development of the body cells along with metabolic power producing processes in $\boldsymbol{m t}$ as powerhouse of cells. Our preceding molecular modeling (DFT/MM) studies validated that antioxidative action of thyroid hormone of T3 and T4 work as superoxide dismutase (SOD) in reductive phosphorylation processes in mitochondria (mt) [3]. These scientific facts predict that the quality and number of active $\boldsymbol{m} \boldsymbol{t}$ is important to sustain the daily functions of $\boldsymbol{m} \boldsymbol{t}$ in cells of healthy human body and then element iodide ion $\left(\mathrm{I}^{-}\right)$is speculated to be vital for formation of iodine-containing chemicals like T3 and T4 in aqueous cells or in $\boldsymbol{m} \boldsymbol{t}$ systems. Biological and chemical processes starting from iodide ion $\left(\mathrm{I}^{-}\right)$and phenylalanine and ending in formation of the iodinated tyrosine derivatives will be analyzed, verified and predicted by DFT/MM using software of Spartan' 18 installed in a PC.

Verification of hydrogen iodide in equilibrium with iodide ion $\left(\mathrm{I}^{-}\right)$in aqueous systems

We speculated that salt of potassium iodide $\left(\mathrm{K}^{+} \mathrm{I}^{-}\right)$must be in equilibrium with hydrogen iodide $\mathrm{H}^{+} \mathrm{I}^{-}$and covalent bonding $\mathrm{H}-\mathrm{I}$ in aqueous system. As shown in Figure 1 and Table S1, aggregates of $\mathrm{K}^{+} \mathrm{I}^{-}$, $\mathrm{H}_{3} \mathrm{O}^{+} \mathrm{I}^{-}$, and $\mathrm{HI} \& \mathrm{H}_{2} \mathrm{O}$ and their hydrated ones, $\mathrm{K}^{+} \mathrm{I}^{-} \& \mathrm{H}_{2} \mathrm{O}, \mathrm{H}_{3} \mathrm{O}^{+} \mathrm{I}^{-} \& \mathrm{H}_{2} \mathrm{O}$ and $\mathrm{HI} \&\left(\mathrm{H}_{2} \mathrm{O}\right)_{2}$ are molecular-modeled for their equilibrium geometry (EQG) and heat of formation $(\Delta \mathrm{E})$. Interestingly, EQG of $\mathrm{H}_{3} \mathrm{O}^{+} \mathrm{I}^{-}$is quite comparable with that of $\mathrm{HI} \& \mathrm{H}_{2} \mathrm{O}$. When each $\Delta \mathrm{E}$ is compared, both aggregates of $\mathrm{HI} \& \mathrm{H}_{2} \mathrm{O}$ and $\mathrm{HI} \&\left(\mathrm{H}_{2} \mathrm{O}\right)_{2}$ form more exothermically. These facts predict that the non-bonded aggregate, $\mathrm{K}^{+} \mathrm{I}^{-} \& \mathrm{H}_{2} \mathrm{O}$ shift to covalent bonded $\mathrm{H}-\mathrm{I}$ species, and $\mathrm{HI} \& \mathrm{H}_{2} \mathrm{O}$ and $\mathrm{HI} \&\left(\mathrm{H}_{2} \mathrm{O}\right)_{2}$ are speculated to be in equilibrium with each other in aqueous systems like blood streams (Figure 1).

Verification of formation of hypoiodous acid (IOH) from hydrogen iodide in aqueous blood systems

In aqueous blood systems, ground state oxygen $\left({ }^{3} \mathrm{O}_{2}\right)$ is in equilibrium with $\mathrm{HOOH}$ which forms from superoxide anion radical of $\mathrm{O}_{2} . \mathrm{DFT} / \mathrm{MM}$ verifies that both ${ }^{3} \mathrm{O}_{2}$ and $\mathrm{O}_{2} \cdot$ aggregate with HI exothermically (Table S2, and Figure 2). EQG of one-electron oxidized states of $\left[\mathrm{H}_{2} \mathrm{O} \& \mathrm{H}-\mathrm{I} \& \& \mathrm{H}_{2} \mathrm{O}\right]^{+}$and of $\left[\mathrm{H}-\mathrm{I} \&\left(\mathrm{H}_{2} \mathrm{O}\right)_{2}\right]^{+}$verify elongation of $\mathrm{H}-\mathrm{I}$ bond distance (respective $3.227,3.774 \AA^{2}$ ) and spatial distance between iodine and oxygen atom of $\mathrm{H}_{2} \mathrm{O}$, decrease to $2.660 \AA$ and $2.954 \AA$ respectively. Radical (Spin) density configuration explains spontaneous formation of hypoiodous acid $(\mathrm{IOH})$ and its hydrated $\mathrm{IOH} \&\left(\mathrm{H}_{2} \mathrm{O}\right)_{2}$ via radical coupling reactions (Table S3, Figure 2).

*Correspondence to: Shozo Yanagida, M3 laboratory, Inc, ISIR, Osaka University, Osaka, Japan, E-mail: yanagida@mls.eng.osaka-u.ac.jp

Key words: mitochondria, molecular mechanics

Received: October 14, 2019; Accepted: November 01, 2019; Published: November 04, 2019 

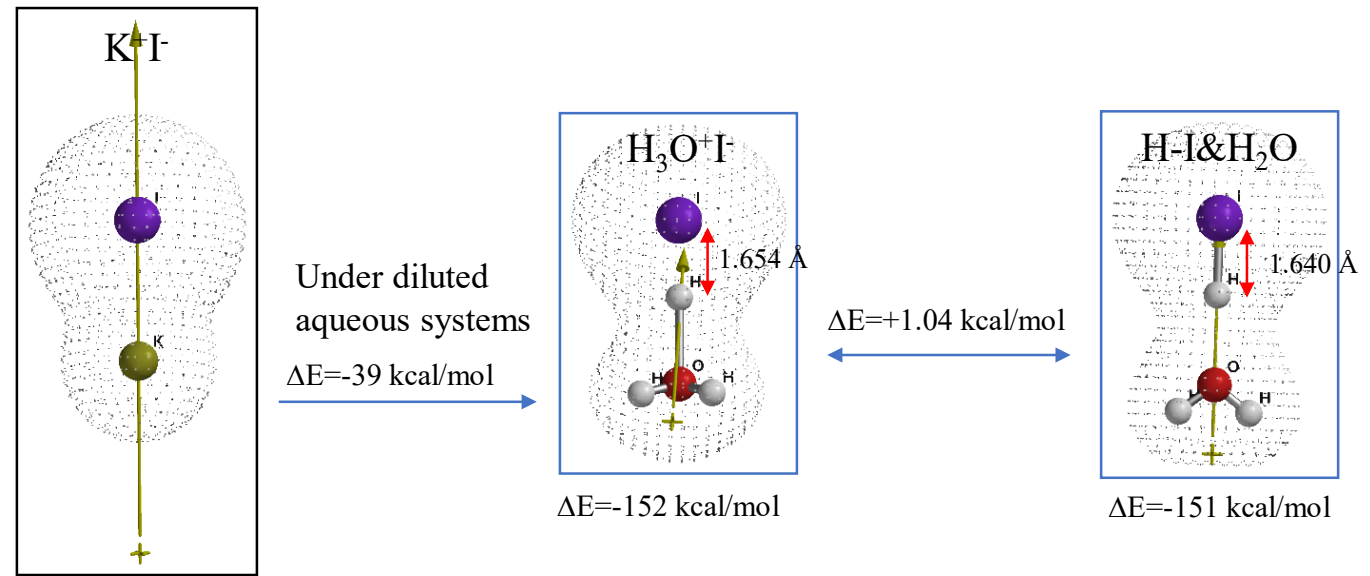

$\Delta \mathrm{E}=-113 \mathrm{kcal} / \mathrm{mol}$

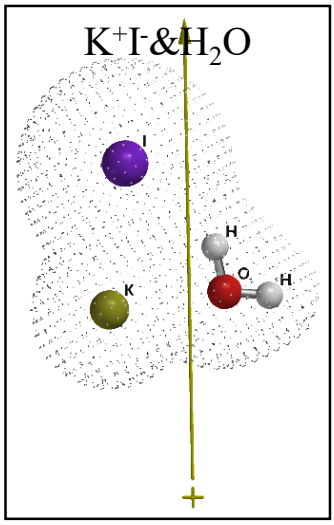

Under diluted aqueous systems

$\Delta \mathrm{E}=-22 \mathrm{kcal} / \mathrm{mol}$

$\Delta \mathrm{E}=-134 \mathrm{kcal} / \mathrm{mol}$
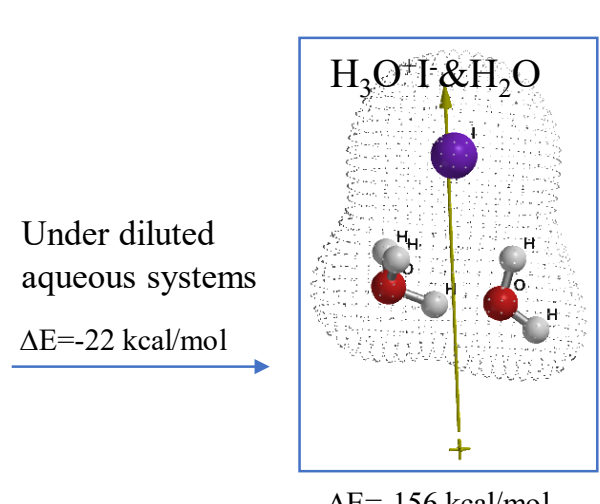

Main equilibrium geometry of $\mathrm{IOH}$ in aqueous systems

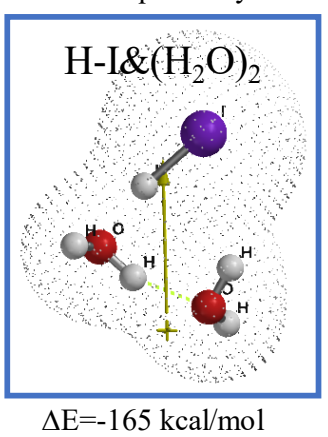

Figure 1. Verification for covalent bonding hydrogen iodide (H-I) under diluted potassium iodide aqueous systems

EQG of vdW aggregates of $\mathrm{H}-\mathrm{I}$ with ${ }^{3} \mathrm{O}_{2}$ and with $\mathrm{HOOH}$


EQG of one-electron oxidation states of vdW aggregates, $\mathrm{H}_{2} \mathrm{O} \& \mathrm{H}-\mathrm{I} \& \mathrm{H}_{2} \mathrm{O}$ and $\mathrm{H}-\mathrm{I} \&\left(\mathrm{H}_{2} \mathrm{O}\right)_{2}$



Figure 2. DFT/MM for formation of IOH via oxidation $\mathrm{H}-\mathrm{I}$ in aqueous systems 


\section{Verification of tyrosine formation through interaction of phenylalanine with $\mathrm{IOH}$}

Figure 3 shows heat of formation $(\Delta \mathrm{E})$ and energy structures determined for vdW aggregate, $\operatorname{IOH} \&\left(\mathrm{H}_{2} \mathrm{O}\right)_{2}$ and ionic bonded aggregate, $\mathrm{I}^{+} \& \mathrm{HO}^{-} \&\left(\mathrm{H}_{2} \mathrm{O}\right)_{2}$. Both potentials of LUMO are negative enough and comparable to one another $(-2.42 \mathrm{eV}$, and $-2.66 \mathrm{eV})$. Heat of formation $(\Delta \mathrm{E})$ for $\mathrm{I}^{+} \& \mathrm{HO}^{-} \&\left(\mathrm{H}_{2} \mathrm{O}\right)_{2} \cdot(\Delta \mathrm{E}=-361 \mathrm{kcal} / \mathrm{mol})$ is much larger than that of $\mathrm{IOH} \&\left(\mathrm{H}_{2} \mathrm{O}\right)_{2}(\Delta \mathrm{E}=-188 \mathrm{kcal} / \mathrm{mol})$. The DFT/MM analysis validates that the two aggregates are in equilibrium with each other but the thermally stable aggregate of $\mathrm{I}^{+} \& \mathrm{HO}^{-} \&\left(\mathrm{H}_{2} \mathrm{O}\right)_{2}$, should work in aqueous systems and $\mathrm{I}^{+}$will be a very active electrophile to phenylalanine.

Quantum chemistry considerations of LUMO in highly reactive electrophilic $\mathrm{I}^{+}$and HOMO of phenylalanine is examined. During reacting interactions between LUMO's and HOMO's, the electrophile $\mathrm{I}^{+}$is allow to position itself on an electron rich para-position, at a perpendicular distance of $1.6 \AA$, and then molecular modeled. The resulting EQG of $\mathrm{I}^{+} \&$ phenylalanine is shown in Figure 4 and Table S4. The EQG reveals that $\mathrm{I}^{+}$positions itself at a distance of $2.261 \AA$, the $\mathrm{C}-\mathrm{H}$ bond on position 4 elongates to $1.093 \AA$, and the $\mathrm{C}-\mathrm{H}$ bonding angle to the face of phenylalanine ring is $114.45^{\circ}$. In addition, the structure of phenylalanine of which para-position both carbon $\mathrm{I}^{+}$and $\mathrm{HO}^{-}$are located at each vertical distance of $1.6 \AA$ is also molecular modeled (Figure 4 and Table S4). The change in bonding distance and the $\mathrm{C}-\mathrm{H}$ bonding angle at para-position are all comparable to those of EQG of $\mathrm{I}^{+} \&$ Phenylalanine. EQG of $\mathrm{I}^{+} \&$ phenylalanine \&HO- looks like transition state to tyrosine via effective aggregation of phenylamine with $\mathrm{IOH}$.
Verification of $\mathrm{IOH}$-induced iodination of tyrosine to

An aggregate of tyrosine with $\mathrm{I}^{+} \& \mathrm{HO}^{-} \& \mathrm{H}_{2} \mathrm{O}$ is optimized by MMFF operation on Spartan'18 and then molecular modeled as summarized in Figure 5 and Table S5. The resulting EQG structure indicates that the nonbonding distance between $\mathrm{I}^{+}$and the ortho carbon $(2,259 \AA)$ is shorter, and the bonding distance (1.866 $\AA$ ) of ring HO group elongates, and the bond angle $\left(147.23^{\circ}\right)$ of $\mathrm{HO}$ at ortho-position to phenyl ring is out of plane, and the bond distance (1.088 $\AA$ ) of $\mathrm{H}-\mathrm{O}$ elongates.

The EQG analysis is true for formation of 2,6-diiodotyrosine from 2 -iodotyrosine as shown in Figure 5 and Table S5. It is worth noting that both heats of formation, $\Delta \mathrm{E}=-250 \mathrm{kcal} / \mathrm{mol}, \Delta \mathrm{E}=-361 \mathrm{kcal} / \mathrm{mol}$ is negative and large and 2,6-diodotyrosine is predicted to be produced in more quantities than 2-iodotyrosine as the amount of T4 (reference interval $8 \sim 17 \mathrm{pg} / \mathrm{mL}$ ) is greater than that of $\mathrm{T} 3$ (reference interval $2.1 \sim 3.1 \mathrm{pg} / \mathrm{mL}$ ) in the blood stream.

\section{Verification of antioxidative effect of 2,6-dioidetyrosine as homologue of thyroid hormone, $\mathrm{T} 4$}

The vdW aggregate of 2,6-diiodotyrosine with $\mathrm{HOOH}$, i.e. $\mathrm{HOOH} \&\left(\mathrm{H}_{2} \mathrm{O}\right)_{2}$ is molecular modeled and the energy structure of the aggregate $\mathrm{HOOH} \&\left(\mathrm{H}_{2} \mathrm{O}\right)_{2} \& 2,6$-diiodotyrosine is compared with those of $\mathrm{HOOH} \&\left(\mathrm{H}_{2} \mathrm{O}\right)_{2}$ (Figure 6). In addition, the LUMO potential $(-1.74$ $\mathrm{eV})$ of $\mathrm{HOOH} \&\left(\mathrm{H}_{2} \mathrm{O}\right)_{2} \& 2,6$-diiodotyrosine is lower than the LUMO potential $(-0.72 \mathrm{eV})$ of $\mathrm{HOOH} \&\left(\mathrm{H}_{2} \mathrm{O}\right)_{2}$, which in fact supports the antioxidative effect of 2,6-diiodetyrosine.
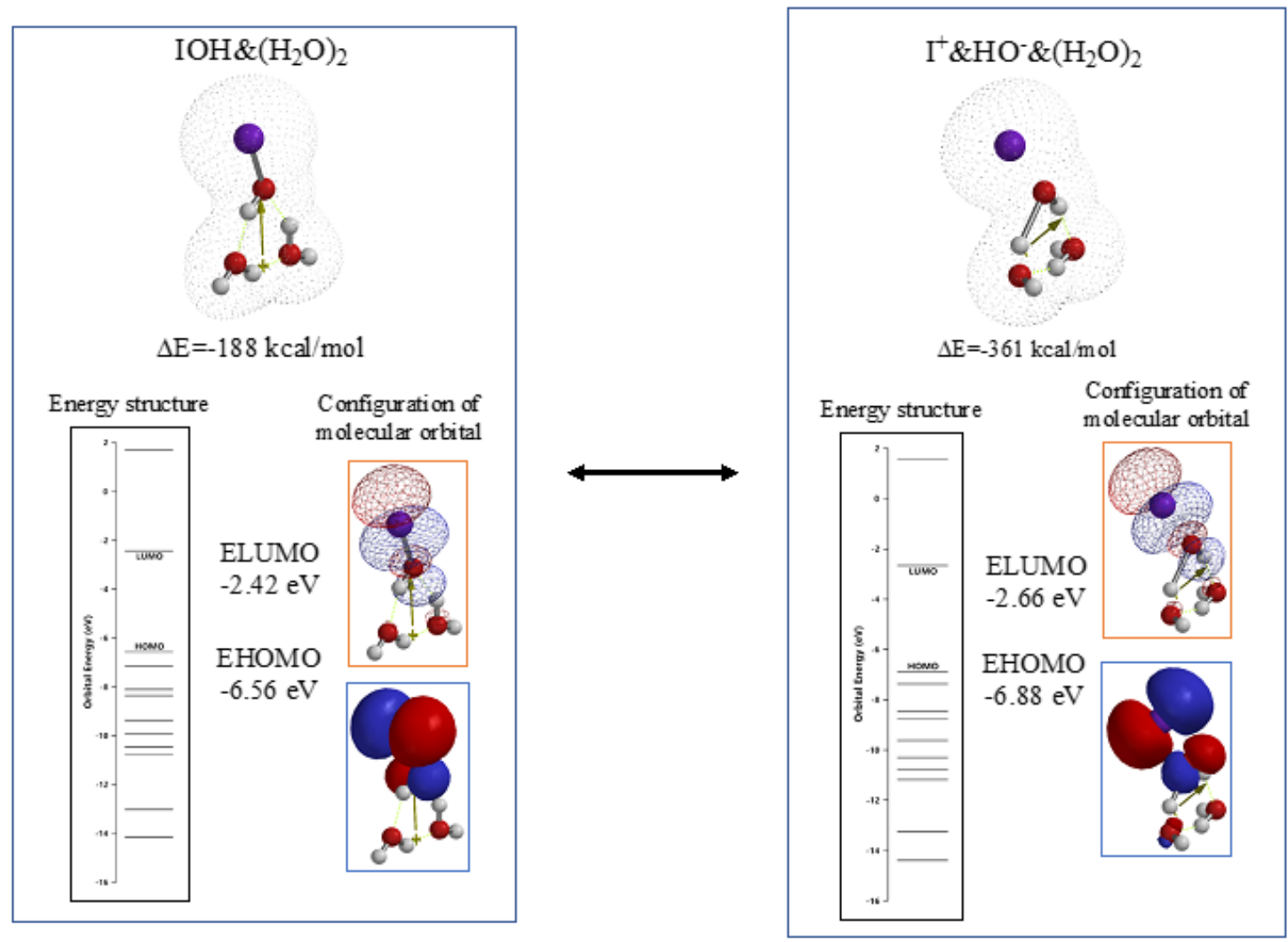

Figure 3. DFT/MM for EQG between $\mathrm{IOH}$ and $\mathrm{I}^{+} \mathrm{OH}^{-}$ 


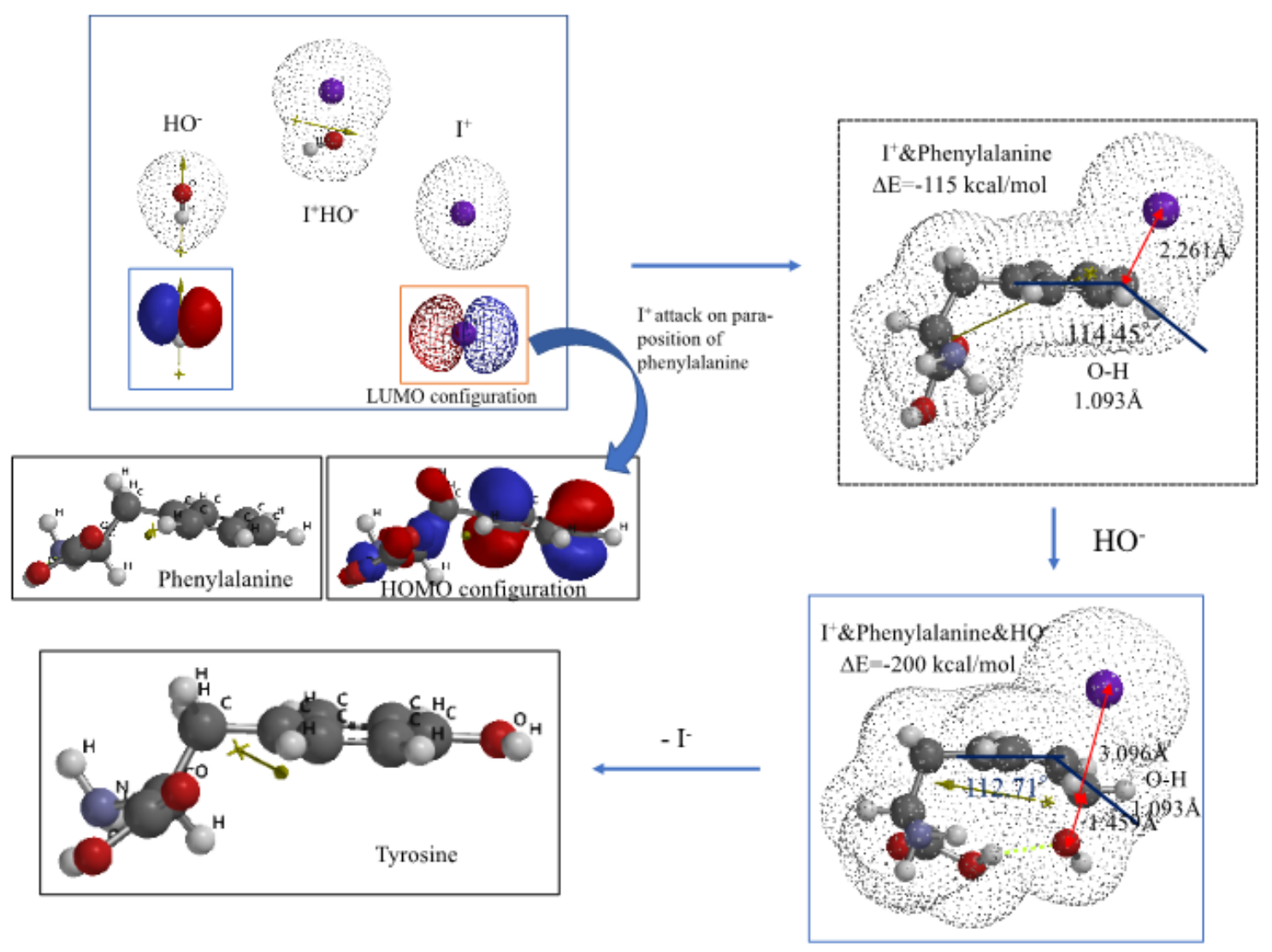

Figure 4. DFT/MM for formation of tyrosine from van der Waals aggregate of phenylalanine and $\mathrm{I}^{+} \mathrm{OH}^{-}$
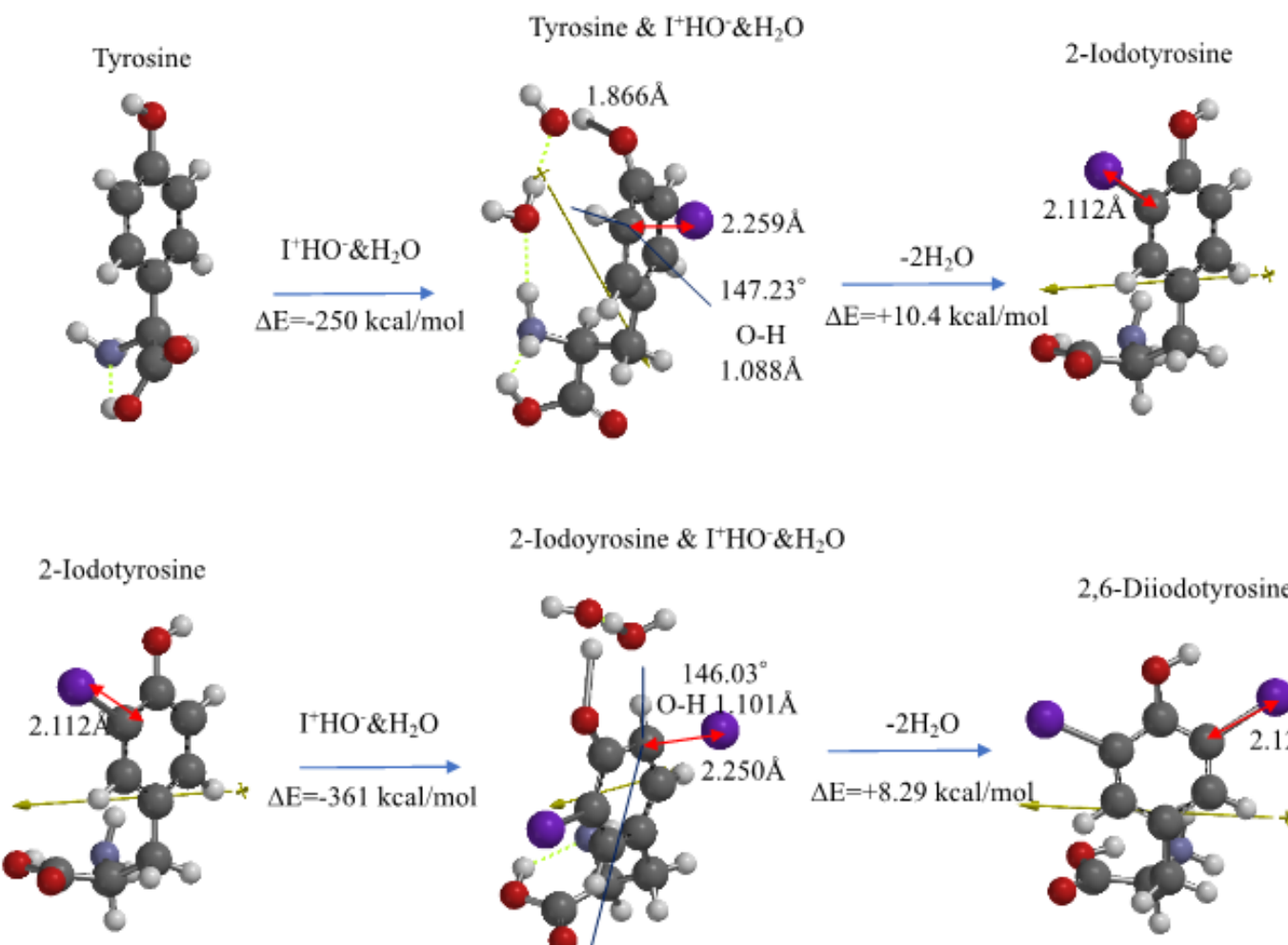

2-Iodoyrosine \& $\mathrm{I}^{+} \mathrm{HO}^{-} \& \mathrm{H}_{2} \mathrm{O}$

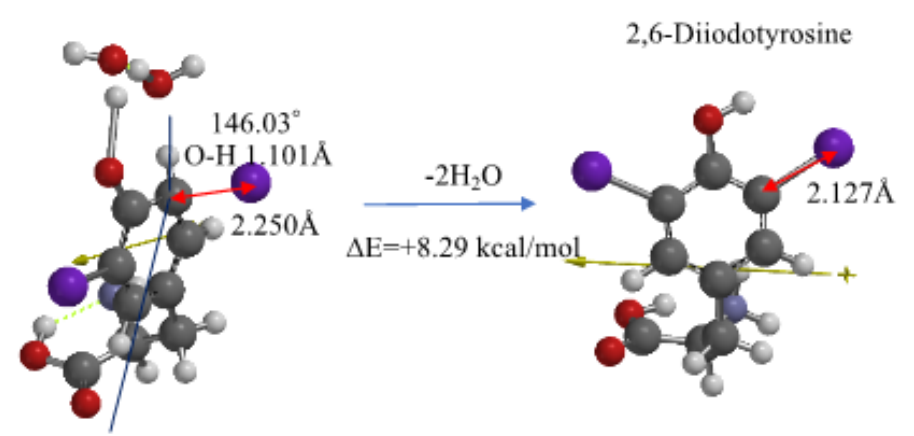

Figure 5. DFT/MM for formation of 2-iodotyrosine and 2,6-diiodetyrosine via van der Waals aggregates with $\mathrm{I}^{+} \mathrm{OH}^{-}$ 
The so-called evil active oxygen, hydroxyl radical (HO) will be produced by reduction of hydrogen peroxide. DFT/MM reveals that hydroxyl radical (HO) itself aggregates with 2,6-diiodotyrosine and increases LUMO potential to a higher $($ EbLUMO $=-2.4 \mathrm{eV})$ than the LUMO potential of $\mathrm{HO} \& \mathrm{H}_{2} \mathrm{O}(\mathrm{EbLUMO}=-3.0 \mathrm{eV})$ (Figure 7, Table
S6). Further, radical (spin) density disappears on the original HO part, delocalizing on the iodine atom-bearing part of the aggregate. The quantum chemistry-based evidence validates decreases in oxidative hydrogen abstraction ability of evil $\mathrm{HO}$ radical (HO).
$\mathrm{HOOH} \&\left(\mathrm{H}_{2} \mathrm{O}\right)_{2} \&$ 2,6-diiodotyrosine

$\Delta \mathrm{E}=-35.6 \mathrm{kcal} / \mathrm{mol}$



$\mathrm{HOOH} \&\left(\mathrm{H}_{2} \mathrm{O}\right)_{2}$

$\Delta \mathrm{E}=-23.8 \mathrm{kcal} / \mathrm{mol}$

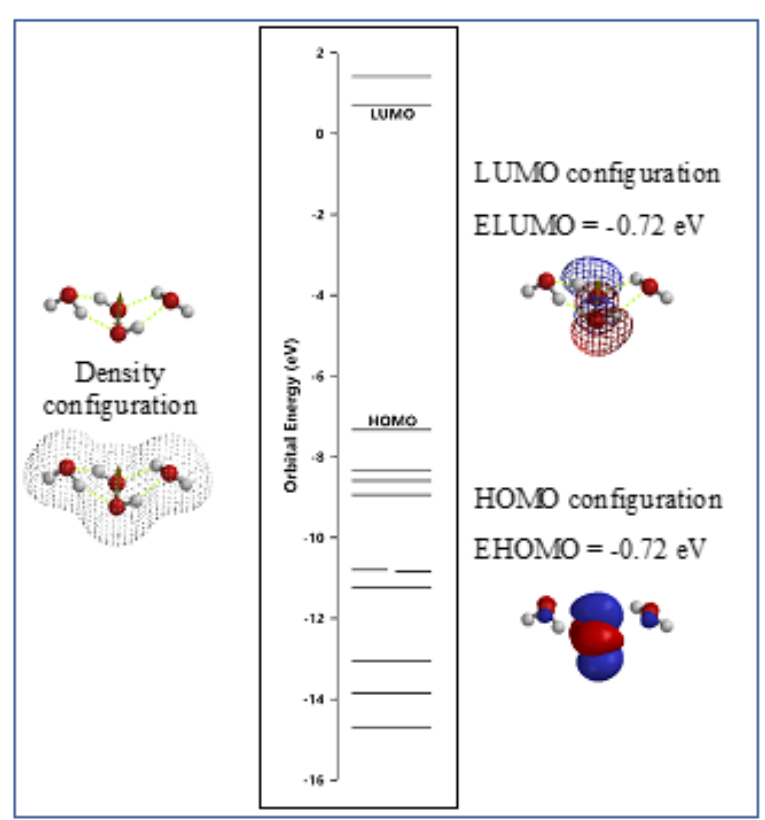

Figure 6. DFT/MM-based verification of antioxidative properties of 2,6-diiodetyrosine

HO $\& \mathrm{H}_{2} \mathrm{O} \& 2,6$-diiodotyrosine

$\Delta \mathrm{E}=-49.5 \mathrm{kcal} / \mathrm{mol}$

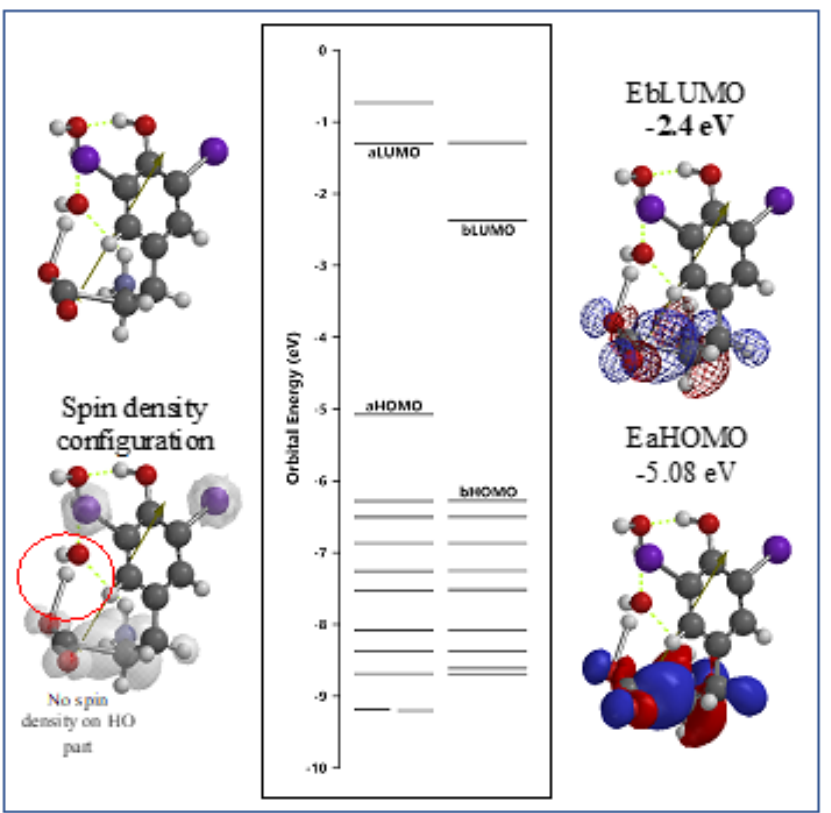

$\mathrm{HO} \& \mathrm{H}_{2} \mathrm{O}$

$\Delta \mathrm{E}=-7.73 \mathrm{kcal} / \mathrm{mol}$



Figure 7. DFT/MM-based verification of antioxidative properties of 2,6-diiodetyrosine toward hydroxyl radical (HO) 


\section{Conclusions}

DFT/MM is useful and gives predictable results for molecular processes in biological chemistry. Dietary intake of acceptable levels of potassium iodide (KI) converting phenylalanine to 2,6-diiodotyrosine via tyrosine and 2-iodotyrosine in body cells has been verified using this method. 6-Diiodotyrosine prevents accumulation of $\mathrm{HOOH}$ in $\boldsymbol{m} \boldsymbol{t}$ just like thyroid hormones, contributing to durability of $\boldsymbol{m} \boldsymbol{t}$ in functioning active cells. Recently, our UV/Vis spectrum analysis combined with DFT/MM have verified that aqueous iodine solution is composed of hydrated $\mathrm{I}_{2}, \mathrm{HI}$ and $\mathrm{IOH}$. When lipid membrane in $\boldsymbol{m} \boldsymbol{t}$ with $0.5-\mu \mathrm{m}$ size undergoes structural disorder by $\mathrm{HOOH}$ and hydroxyl radical ( $\mathrm{HO}$ ), they may look swollen. The swollen lipid membrane of $\boldsymbol{m} \boldsymbol{t}$ will make $\boldsymbol{m} \boldsymbol{t}$ look like cancer tissue. DFT/MM for anticancer activity of iodide will be reported in the near future.

\section{Acknowledgements}

The authors thank Dr. Kenji Osabe (ISRI, Osaka University, Osaka, Japan) for discussion on quantum chemistry molecular modeling for durability of mitochondria.

\section{References}

1. Preeti Tomar Bhattacharya, Satya Ranjan Misra, Mohsina Hussain (2016) Nutritional Aspects of Essential Trace Elements in Oral Health and Disease: An Extensive Review. Scientifica 2016: 1-12

2. Search on the internet using key words "essential element for health, iodine": e.g., you will find "Linus Pauling Institute, Healthy aging program".

3. Shozo Yanagida, Kenji Osabe, Takeharu Nagai, Nobuyuki Murakami (2019) Quantum chemistry molecular modeling for longevity: Importance of antioxidative effects in mitochondria as battery of cells. Integr Mol Med 6: 1-10.

Copyright: (C2019 Yanagida S. This is an open-access article distributed under the terms of the Creative Commons Attribution License, which permits unrestricted use, distribution, and reproduction in any medium, provided the original author and source are credited. 